\title{
A OTIMIZAÇÃO DA CONTABILIDADE GERENCIAL E \\ CONTROLADORIA BASEADO NO SISTEMA DE GERENCIAMENTO DE OPERAÇÕES FINANCEIRAS
}

\author{
OPTIMIZATION OF MANAGEMENT ACCOUNTING \\ AND CONTROLLERSHIP BASED ON FINANCIAL OPERATIONS \\ MANAGEMENT SYSTEM.
}

\author{
Marcelo Eloy Fernandes \\ Doutorado em Engenharia de Produção Universidade \\ Metodista de Piracicaba, UNIMEP, Brasil. \\ Eric Renato da Silva \\ Especialista em Finanças e Banking \\ Universidade Nove de Julho, São Paulo, Brasil
}

\section{RESUMO}

Este estudo de caso focou no resultado positivo que o Sistema de Gerenciamento de Operações Financeiras (T-800), trouxe a Contabilidade Gerencial e Controladoria da empresa Engenharia e Construção ERO. Também mostrará como trouxe dinamismo e facilidade para a Tomada de Decisão para com as oscilações das disponibilidades de caixa que a tesouraria matriz enfrenta em seu dia-a-dia. O objetivo do artigo é demonstrar recursos que facilitam o gerenciamento das operações financeiras e facilitam para tomada de decisão. $\mathrm{O}$ artigo buscou dados através de relatórios anuais que a tesouraria e controladoria consolidam para reunião anual que ocorre para apresentação de resultado.O resultado final do estudo indica que a empresa focou na escolha neste Sistema de Gerenciamento de Operações Financeiras (T800) visando melhora, alto desempenho e competitividade nos processos internos de seus Controllers e Tesoureiros.

Palavras-chave: Sistema de Gerenciamento de Operações Financeiras (T-800), Contabilidade Gerencial e Controladoria, Tomada de Decisão, Controllers e Tesoureiros.

\begin{abstract}
This case study focused on the positive outcome which System of Financial Operations Management (T-800) has brought Management Accounting and Controllership Engineering and Construction Company ERO. It also showed how has brought dynamism and facility for decision making toward the oscillations from available cash matrix treasury confronts in its day to day. The aim of the paper is to demonstrate features that facilitate the financial operations management and to make it easy the decision making. The article searched data through annual reports which treasury and controllership to consolidate annual meeting that takes place for submission of the result. The final result of this study suggests that the company focused on choosing this Financial Operations Management System (T-800) aiming at improvement, high performance and competitiveness in the internal processes of their controllers and treasurers.
\end{abstract}

Keywords: Management System Financial Operations (T-800), Managerial Accounting and Control, Decision Making, Controllers and Tesoureiros. Treasurers. 


\section{1 - INTRODUÇÃO}

Cada vez mais as organizações precisam melhorar seus processos internos, adquirir conhecimento, controlar melhor seus gastos e investimentos, conquistar mais clientes e apresentar resultados positivos para seus "StakeHolders e StockHolders", e com esse objetivo, a empresa de Engenharia e Construção ERO, cotou cuidadosamente e escolheu um sistema de gerenciamento de operações financeiras, que atendesse toda a particularidade que o seu negócio exigisse, sem perder a flexibilidade e rapidez para tomada de decisão que seus controllers e tesoureiros enfrentam diariamente.

O sistema selecionado foi da empresa T-800, a ferramenta Universe Web - Cash and Treasury Management, que disponibiliza os seguintes recursos para gestão de tesouraria

-Gestão de caixa, Planejamento e liquidez, Reconciliação bancária, Pagamentos e Operações Financeiras.

Em Operações Financeiras, teremos as principais ferramentas de um controller, destinada a uma rica gestão de suas operações, sendo elas:

-Gestão das operações ativas e passivas, como aplicações, financiamentos de curto, médio e longo prazo, leasing, swap, derivativo, debênture, fiança bancária, garantias, seguros, mútuos, câmbio, opções, termos, etc. Avaliação de rentabilidade da carteira, benchmark em índices econômicos, posição de endividamento de curto e longo prazo, exposição por bancos, moedas, índices, simulação de operações, marcação a mercado, contabilização, boletagem, etc.

Este trabalho foi desenvolvido com uma visão voltada para a estratégia da empresa, onde executivos necessitam da inteligência do negócio para conseguirem alcançar seus objetivos.

\section{2 - FUNDAMENTAÇÃO TEÓRICA}

\section{1 - SISTEMAS DE INFORMAÇÃO}

Os sistemas de informação têm por objetivo gerar informações para a tomada de decisões, os dados são coletados, processados e transformados em informação.

Stair (1998, p. 11), afirma que: os sistemas de informação é uma série de elementos ou componentes inter-relacionados que coletam (entrada), manipulam e armazenam (processo), disseminam (saída) os dados e informações e fornecem um mecanismo de feedback.

Gil (1999, p.14), define que “... os sistemas de informação compreendem um conjunto de recursos humanos, materiais, tecnológicos e financeiros agregados segundo uma seqüência lógica para o processamento dos dados e a correspondente tradução em informações.

Pereira e Fonseca (1997, p. 241), “...os sistemas de informação (management information systems) são mecanismos de apoio à gestão, desenvolvidos com base na tecnologia de informação e com suporte da informática para atuar como condutores das informações que visam facilitar, agilizar e otimizar o processo decisório nas organizações.

A gestão empresarial precisa cada dia mais do apoio de sistemas, pois estes dão segurança, agilidade e versatilidade para a empresa no momento em que se processam as decisões.

\subsection{1 - FINALIDADES DOS SISTEMAS DE INFORMAÇÃO}


As empresas precisam estar preparadas para lidar com os problemas internos e externos do ambiente em que estão inseridas, para tanto buscam no desenvolvimento de sistemas de informações suporte para a resolução desses problemas.

Laudon e Laudon (1999, p. 26), afirmam que a razão mais forte pelas quais as empresas constroem os sistemas, então, é para resolver problemas organizacionais e para reagir a uma mudança no ambiente.

Os sistemas de informação objetivam a resolução de problemas organizacionais internos, e a consequente preparação para enfrentar as tendências da crescente competitividade de mercado.

Para Pereira e Fonseca (1997, p. 241), os sistemas de informação têm por finalidade de captura e/ou a recuperação de dados e sua análise em função de um processo de decisão.

Envolvem, de modo geral, o decisor, o contexto, o objetivo da decisão e a estrutura de apresentação das informações.

De forma estruturada, os sistemas de informação dão condições para que as empresas reajam às mutações do mercado e se sintam alicerçadas por um processo decisório forte o suficiente para garantir a resolução dos problemas.

\subsection{2 - EXPECTATIVAS DOS SISTEMAS DE INFORMAÇÃO}

A necessidade do Sistema de Informação (SI) nas empresas surgiu devido ao grande e crescente volume de informações que a organização possui. Com o Sistema de Informação estruturado a apresentação das informações necessárias e também já propiciando uma visão das decisões, a empresa garante um grande diferencial em relação aos concorrentes, e os gestores podem tomar decisões mais rápidas e de fontes seguras.

A exigência do mercado, competitivo, dinâmico e principalmente globalizado motiva as empresas a operarem com um sistema de informação eficiente, garantindo níveis mais elevados de produtividade e eficácia.

Segundo Batista (2004, p. 39), o objetivo de usar os sistemas de informação é a criação de um ambiente empresarial em que as informações sejam confiáveis e possam fluir na estrutura organizacional.

$\mathrm{Na}$ era da informação, o diferencial das empresas e dos profissionais está diretamente ligado à valorização da informação e do conhecimento, proporcionando soluções e satisfação no desenvolvimento das atividades.

Para serem efetivos, os sistemas de informação precisam, segundo Pereira e Fonseca (1997, p. 242), corresponder às seguintes expectativas:

- Atender as reais necessidades dos usuários;

- Estar centrados no usuário (cliente) e não no profissional que o criou;

- Atender ao usuário com presteza;

- Apresentar custos compatíveis;

- Adaptar-se constantemente às novas tecnologias de informação;

- Estar alinhados com as estratégias de negócios da empresa.

Ao visualizar um sistema que atenda os requisitos acima, a empresa se sente confiante no momento de utilizá-lo no processo decisório de seus negócios. 


\subsection{3 - SISTEMAS DE INFORMAÇÃO GERENCIAL (SIG)}

O sistema de informação gerencial dá suporte às funções de planejamento, controle e organização de uma empresa, fornecendo informações seguras e em tempo hábil para tomada de decisão.

Oliveira (2002, p. 59), define que o sistema de informação gerencial é representado pelo conjunto de subsistemas, visualizados de forma integrada e capaz de gerar informações necessárias ao processo decisório.

Garcia e Garcia (2003, p. 29) definem que sistema de informação gerencial: é qualquer sistema que produza posições atualizadas no âmbito corporativo, resultado da integração de vários grupos de sistemas de informação que utilizam recursos de consolidação e interligação de entidades dentro de uma organização.

Stair (1998, p.278), assim define o propósito básico de um SIG é ajudar a empresa a alcançar suas metas, fornecendo a seus gerentes detalhes sobre as operações regulares da organização, de forma que possam controlar, organizar e planejar com mais efetividade e com maior eficiência.

Os executivos devem buscar projetar os sistemas de informação gerencial inserindo dados de origem interna e externa, existindo portando, uma interação entre os meios, resultando na concretização dos objetivos preestabelecidos pela empresa.

As fontes externas advêm do relacionamento com fornecedores, acionistas, clientes e concorrentes, facilitadas nas atuais circunstâncias pela evolução tecnológica.

As fontes internas estão relacionadas aos bancos de dados mantidos pela organização.

Os bancos de dados são atualizados pela captura e armazenamento dos dados resultantes da integração dos diversos sistemas que compõem a organização, entre eles, sistemas de finanças, sistemas de contabilidade, sistemas de recursos humanos, sistemas de venda e marketing.

Oliveira (1992, p. 39), afirma que Sistema de Informação Gerencial (SIG) é o processo de transformação de dados em informações que são utilizadas na estrutura decisória da empresa, proporcionando, ainda, a sustentação administrativa para otimizar os resultados esperados.

Os sistemas de informação gerencial mudam constantemente para atender o dinamismo dos negócios, o que vai de encontro à necessidade de qualquer organização para sobreviver no mercado.

Para Batista (2004, p. 22), sistema de informação gerencial é o conjunto de tecnologias que disponibilizam os meios necessários à operação do processamento dos dados disponíveis.

È um sistema voltado para a coleta, armazenagem, recuperação e processamento de informações usadas ou desejadas por um ou mais executivos no desempenho de suas atividades. É o processo de transformação de dados em informações que são utilizadas na estrutura decisória da empresa proporcionam a sustentação administrativa para otimizar os resultados esperados.

A estrutura decisória da empresa, no contexto de processos gerenciais, classifica os sistemas de acordo com o problema organizacional que ajuda a resolver.

Batista (2004) escreve que os sistemas são classificados em: sistema de nível estratégico, de conhecimento,tático e operacional. As informações geradas pelos sistemas de nível estratégico são utilizadas na definição do planejamento estratégico da organização, ou seja, tomada de decisão.

Os sistemas de nível tático são usados no controle dos planejamentos operacionais, define as táticas ou metas a serem cumpridas. Os sistemas de conhecimento envolvem a transmissão de conhecimento e informação entre os departamentos. Os sistemas de nível 
operacional são utilizados para o desenvolvimento das tarefas diárias da empresa, como exemplo: sistema de compra/venda.

\subsection{4 - IMPORTÂNCIAS DOS SISTEMAS DE INFORMAÇÃO GERENCIAL PARA AS EMPRESAS}

Tem-se dificuldade em avaliar quantitativamente os benefícios oferecidos por um sistema de informação gerencial, porém Oliveira (2002, p.54) afirma que o sistema de informação gerencial pode, sob determinadas condições, trazer os seguintes benefícios para as empresas:

- Redução dos custos das operações;

- Melhoria no acesso às informações, proporcionando relatórios mais precisos e rápidos, com menor esforço;

- Melhoria na produtividade;

- Melhoria nos serviços realizados e oferecidos;

- Melhoria na tomada de decisões, por meio do fornecimento de informações mais rápidas e precisas;

- Estímulo de maior interação dos tomadores de decisão;

- Fornecimento de melhores projeções dos efeitos das decisões;

- Melhoria na estrutura organizacional, para facilitar o fluxo de informações;

- Melhoria na estrutura de poder, proporcionando maior poder para aqueles que entendem e controlam os sistemas;

- Redução do grau de centralização de decisões na empresa;

- Melhoria na adaptação da empresa para enfrentar os acontecimentos não previstos.

Essas premissas permitem que as empresas definam possíveis fortalecimentos do processo de gestão, garantindo o diferencial de atuação e por consequiência, vantagem competitiva.

Os sistemas de informação gerencial segundo Stair (1998), resulta em vantagem competitiva para a empresa, pois um SIG deve ser desenvolvido de forma a dar apoio às metas da organização. Por exemplo, os executivos de nível superior usam relatórios do SIG no desenvolvimento de estratégias para o sucesso dos negócios, os gestores de nível médio usam os relatórios de SIG para comparar as metas estabelecidas da empresa com os resultados reais.

Dessa forma, a empresa justifica o cumprimento de suas metas com a ajuda dos sistemas de informação gerencial.

\subsection{5 - ASPECTOS QUE FORTALECEM OS SISTEMAS DE INFORMAÇÃO GERENCIAL NAS EMPRESAS}

Os sistemas de informação gerenciais são instrumentos para o processo decisório. Por conseqüência, para que a empresa possa usufruir as vantagens básicas dos Sistemas de Informação Gerenciais, é necessário, segundo Rezende e Abreu (2000,

p. 121), que alguns aspectos sejam observados. Entre estes podem ser citados:

- O envolvimento da alta e média gestão;

- A competência por parte das pessoas envolvidas com o SIG;

- O uso de um plano mestre ou planejamento global;

- A atenção específica ao fator humano da empresa;

- A habilidade dos executivos para tomar decisões com base em informações

- O apoio global dos vários planejamentos da empresa;

- O apoio organizacional de adequada estrutura organizacional e das normas e procedimentos inerentes ao sistema; 
- O conhecimento e confiança no SIG;

- Existência de e/ou informações relevantes e atualizadas;A adequação custo-benefício.

As mudanças nos processos empresariais são inevitáveis quando se opta por investir em inovação, principalmente com relação à tecnologia.

\subsection{6 - RELATÓRIOS DO SISTEMA DE INFORMAÇÃO GERENCIAL}

Os relatórios do sistema de informação gerencial podem ajudar os administradores no que tange os aspectos de desenvolvimento de planos para melhorar a administração, assim como obter melhor controle sobre as operações da empresa, e tomar decisões acertadas.

O processo de transformação de dados resulta em informações úteis que podem ser observadas nos relatórios.

Stair (1998), escreve que os relatórios advindos do sistema de informação gerencial incluem relatórios programados, relatório indicador de pontos críticos, relatórios sob solicitação e relatórios de exceção:

a) Os relatórios programados são aqueles produzidos periodicamente, por exemplo, em uma fábrica a produção de um determinado produto pode ser monitorado diariamente.

b) O relatório de pontos críticos é um tipo especial de relatório programado emitido no começo de cada dia, resumindo as atividades do dia anterior.

Os administradores obtêm informações sobre as atividades críticas da empresa possibilita ações corretivas. Os relatórios sob solicitação são produzidos somente quando o administrador quer saber sobre um item específico, por exemplo, total da venda de um determinado produto. Os relatórios de exceção são parametrizados para informar automaticamente critérios preestabelecidos pela empresa, por exemplo, para se ter um efetivo controle de estoque os administradores parametrizam o sistema para avisar quando determinado produto está com estoque abaixo do mínimo ideal.

Diante deste contexto, pode-se concluir que os relatórios produzidos pelo sistema de informação gerencial deveriam ser fornecidos de acordo com a necessidade dos gerentes,tais relatórios podem ser diários, semanais, mensais e apresentar informações de cunho financeiro, administrativo, e contábil.

\section{2 - CONTABILIDADE}

De acordo com Oliveira (2000), a contabilidade é fundamental para o controle e o acompanhamento das atividades econômicas e empresariais. Em sentido mais amplo, ela trata da coleta, classificação, apresentação e interpretação das informações e dados econômicos, operacionais e financeiros das companhias.

Segundo Gil (1992):

"Pode-se entender contabilidade com sendo a ciência que estuda e controla o
patrimônio das entidades, mediante o registro, a demonstração expositiva e a
interpretação dos fatos nele ocorridos, com o fim de oferecer informações
sobre sua composição e variações, bem como sobre o resultado econômico
decorrente da gestão da riqueza patrimonial." (Gil ,1992)

Ribeiro (1997, p. 14) assinala a contabilidade é uma ciência que permite, através de suas técnicas, manter um controle permanente do patrimônio da empresa.

Ribeiro (1997, p. 15) aponta que o campo de aplicação da Contabilidade abrange todas as entidades econômico-administrativa, até o mesmo as pessoas de direito público, como a União, os Estados, os municípios, as Autarquias, entre outras. 


\subsection{1 -DIVISÕES DA CONTABILIDADE}

Oliveira (2000) esclarece que a contabilidade compreende quatro áreas principais, a contabilidade financeira, a contabilidade fiscal ou tributária, a contabilidade de custos de produção de bens ou serviços e por último, a contabilidade gerencial. Estas quatro divisões da contabilidade podem ser melhor verificadas abaixo:

a) Contabilidade financeira: caracteriza-se pelos controles, demonstrações e metodologias que devem ser obedecidos para que sejam cumpridas plenamente as obrigaçõeslegais e fiscais às quais estão sujeitas as pessoas jurídicas. Para o cumprimento dessas obrigações foram estabelecidas leis, princípios, postulados e convenções relativas à matéria contábil, que visam a padronização e à uniformização das informações geradas pela empresa.

Tal padronização torna a contabilidade financeira rígida demais para a necessidade de informações dos níveis gerenciais, necessitando uma contabilidade paralela, livre dessa padronização chamada de contabilidade gerencial;

b) contabilidade fiscal ou tributária: caracteriza-se pelo controle dos prazos de recolhimento dos diversos tributos e conseqüente registro contábil das provisões relativas aos tributos a recolher, conforme os Princípios Fundamentais da Contabilidade;

c) contabilidade de custos de produção de bens ou serviços: a contabilidade de custos possui algumas características principais, entre as quais se destacam: contribuir para o aprimoramento do sistema de controles internos; fornecer subsídios para o cálculo do custo das vendas; ajudar a eliminar desperdícios e apurar os resultados por produto e por departamento. Devido à necessidade de informações por parte dos gestores, a contabilidade de custos passou a gerar informações para a confecção de relatórios que auxiliem na tomada de decisão;

d) contabilidade gerencial pode ser caracterizada como um enfoque especial conferido às várias técnicas e procedimentos contábeis já conhecidos e tratados na contabilidade financeira, na contabilidade de custos, nas análises financeiras e de balanços, etc., colocados numa perspectiva diferente, num grau de detalhamento mais analítico ou numa forma de apresentação e classificação diferenciada, de maneira a auxiliar os gerentes das entidades em seu processo decisório.

\subsection{2 - CONTABILIDADE GERENCIAL VERSUS CONTABILIDADE FINANCEIRA}

Segundo Padoveze (1998), os métodos da contabilidade financeira e da contabilidade gerencial foram desenvolvidos para diferentes propósitos e para diferentes usuários das informações financeiras. Há, contudo, numerosas similaridades e áreas de sobreposição entre os métodos da contabilidade financeira e da gerencial.

A contabilidade gerencial é relacionada com o fornecimento de informações para os administradores, já a contabilidade financeira está relacionada com o fornecimento de informações para os acionistas, credores e outros que estão fora da organização. 


\subsection{3 - CONTROLADORIA}

A definição constante da clássica obra de Mossimann, Alves e Fisch (1993,p.2) já deixava clara a existência de duas grandes possibilidades mutuamente excludentes por representarem categorias lógicas diversas, pois a Controladoria consiste em um corpo de doutrinas e conhecimentos relativos à gestão econômica e pode ser visualizada sob dois enfoques:

a) como órgão administrativo, com uma missão, função e princípios norteadores definidos no modelo de gestão do sistema empresa; e

b) como uma área de conhecimento humano com fundamentos, conceitos, princípios e métodos oriundos de outras ciências.

$\mathrm{Na}$ continuidade do assunto, Alves e Fisch (1993) explicam ainda que na continuidade da primeira hipótese, que a controladoria representa, um setor da empresa, com funções definidas, integrado na sua estrutura. Noutras palavras, é parte de um organograma funcional, o qual, como é normal, obedece a determinados princípios ou diretivas. Já na segunda conceituação configura, conforme declarado, área de conhecimento humano. Curiosamente, os autores em causa não lhe conferem autonomia, porquanto afirmam sua fundamentação epistemológica em outras ciências, o que significa que a controladoria não é uma ciência, pois todas as ciências devem ter, pelo menos, objeto e objetivos próprios. Mais adiante, na mesma obra, encontramos nova conceituação, especificando quais são as ciências referidas na definição da alínea $b$ :

\footnotetext{
“A controladoria pode ser conceituada como um conjunto de princípios, procedimentos e métodos das Ciências da Administração, Economia, Psicologia, Estatística, e principalmente da Contabilidade, que se ocupam da gestão econômica das empresas, com o fim de orientá-las para eficácia.” (Mossimann, Alves e Fisch ,1993)
}

Figueiredo e Caggiano (1997, p.3) comentam o resultado da revisão da literatura e da prática empresarial, concluindo que as responsabilidades e as atividades básicas da Controladoria incluem o planejamento, o controle e a avaliação de desempenho, a preparação e a interpretação de informações, a contabilidade geral e de custos e outras atividades que impactam o desempenho empresarial.

O tema predominante na obra concerne à contabilidade de custos no sentido amplo, incluindo a análise de custos, o planejamento orçamentário - abrangendo investimentos -, os preços de venda e os controles internos no sentido amplo.

Catelli (2001, p.4), apesar de a sua conhecida obra conter muitas críticas contundentes à Contabilidade, apoiadas predominantemente em autores norte- americanos, afirma que:

A controladoria enquanto ramo do conhecimento, apoiada na Teoria da Contabilidade e numa visão multidisciplinar, é responsável pelo estabelecimento das bases teóricas e conceituais necessárias para a modelagem, construção e manutenção de sistemas de Informações e Modelo de Gestão Econômica, que supram adequadamente as necessidades informativas dos Gestores e os induzam durante o processo de gestão, quando requerido, a tomarem decisões ótimas.

Curiosamente, embora que a Controladoria constitui ramo do conhecimento reconhece que está apoiada na Teoria da Contabilidade, apesar de não esclarecer em qual teoria ou doutrina contábil, pois reconhecidamente há muitas, sendo, o que ainda é pior, algumas contraditórias entre si. De qualquer forma, coloca no centro das atenções os sistemas de informação e a existência de modelos ou parâmetros de gestão econômica, de maneira que aqueles possam suprir os gestores com os elementos para a tomada de decisões corretas. Mas o que interessa nos termos do presente trabalho é o fato de afirmar que a controladoria está fundamentada na Teoria da Contabilidade, embora em momento algum desenvolva pelo menos os lineamentos da teoria a qual está se referindo. 
Constitui igualmente referência a obra de Nakagawa (1993. p 5), que, já na primeira página, relaciona as palavras Controladoria e Controller:

Os modernos conceitos de Controladoria indicam que o Controller desempenha sua função de controle de maneira muito especial, isto é, ao organizar e reportar dados relevantes, exerce uma força de influência que induz os gerentes a tomarem decisões lógicas e consistentes com a missão e objetivos da empresa.

\subsection{4 - TOMADA DE DECISÕES}

Tomada de decisões é o processo pelo qual são escolhidas algumas ou apenas uma entre muitas alternativas para as ações a serem realizadas.

Gomes et al. (2006) definem que o conceito do vocábulo decisão é constituído por de (que vem do latim e significa parar, extrair, interromper) que se antepõe à palavra caedere (que significa cindir, cortar). Sendo assim, literalmente significa "parar de cortar" ou "deixar fluir.

Chiavenato (1997, p.710) elucida ao definir decisão como o processo de análise e escolha entre várias alternativas disponíveis do curso de ação que a pessoa deverá seguir.

Gomes et al. (2006) Decidir é posicionar-se em relação ao futuro.

Tomada de decisão, segundo Oliveira (2004), nada mais é do que a conversão das informações em ação, assim sendo, decisão é a ação tomada com base na apreciação de informações. Decidir é recomendar entre vários caminhos alternativos que levam a determinado resultado.Em se tratando das decisões tomadas sob certeza, o decisor tem conhecimento das conseqüências ou resultados de todas as alternativas, sendo assim, pode escolher a melhor dentre as alternativas propostas.

Stephen e Coulter (1996, p. 126), enfatizam que a situação ideal para a tomada de decisões é a de certeza, ou seja, o administrador pode tomar decisões precisas, pois o resultado de cada alternativa é conhecido.

\subsection{5 - ELEMENTOS DE DECISÃO}

Segundo Chiavenato (1997), as decisões possuem fundamentalmente seis elementos: atuação.

a) Tomador de decisão - pessoa que faz a seleção entre várias alternativas de

b) Objetivos - propósito ou finalidade que o tomador de decisão almeja alcançar com sua ação.

c) Preferências - critérios com juízo de valor do tomador de decisão que vai distinguir a escolha.

d) Estratégia - direção ou caminho que o tomador de decisão sugere para melhor atingir os objetivos e que depende dos recursos que se dispõe.

e) Situação: aspectos ambientais dos quais vela-se o tomador de decisão, muitos dos quais fora do controle, conhecimento ou compreensão e que afetam a opção.

f) Resultado: é a decorrência ou resultante de uma dada estratégia definida pelo decisor. 


\subsection{6 - OPERAÇÕES FINANCEIRAS}

Iudícibus (2000), explica que as empresas comerciais também são envolvidas por operações financeiras, pois, quando necessitam de capital de giro, recorrem aos instrumentos ofertados pelo mercado financeiro e, quando têm sobras de caixa, também buscam oportunidades de investimento para seus recursos.

\section{Aplicações}

Stephen et al. (2000) entende que aplicação financeira é a compra de um ativo financeiro, na expectativa de que, no tempo, produza um retorno financeiro, ou seja, espera-se não só obter o capital investido, como também um excedente, a título de juros ou dividendos, ou seja, são operações onde há uma saída inicial de caixa a título de investimento, com a expectativa de resgate acrescido de rendimentos, ao final de períodos pré-estabelecidos ou em aberto.

\section{Captações}

Assaf (2001.p.105) o mercado de crédito visa fundamentalmente suprir as necessidade de caixa de curto e médio prazos dos vários agentes econômicos, seja por meio da concessão de créditos as pessoas físicas ou empréstimos e financiamentos as empresas, resuma-se que são operações onde há uma entrada inicial de caixa a título de empréstimo, com o compromisso de pagamento acrescido de juros, também ao final de períodos pré-estabelecidos ou em aberto.

\section{Mútuos}

Ribeiro (1997) entende que: O contrato de mútuo é um empréstimo em dinheiro, sendo muito comum entre sociedades que tenham ligação entre si ou entre sociedade e seus respectivos sócios pessoa física. Tudo se passa como se a mutuante estivesse fazendo uma Aplicação e, portanto, recebendo juros e incidindo em Imposto de Renda, e a mutuaria estivesse fazendo uma Captação e, portanto, pagando os mesmos juros por isso e incidindo em Imposto sobre Operações de Crédito. São operações em que a empresa mutuante cede numerário à empresa mutuária, ambas obrigatoriamente cadastradas como empresas no Sistema.

\section{Leasing}

Assaf (2000) a operação de arrendamento mercantil pode ser compreendida como uma forma especial de financiamento. Essa modalidade é praticada mediante a celebração de um contato de arrendamento efetuado entre um cliente e uma sociedade de arrendamento mercantil. O Leasing ou Arrendamento Mercantil é uma operação onde o proprietário (arrendador) de um bem, móvel ou imóvel, cede o uso deste bem a um terceiro (arrendatário), por prazo determinado, recebendo em troca uma prestação periódica. Ao final do Contrato, o arrendatário tem o direito de compra ou não do bem, pelo valor residual estipulado.

\section{Hedge sem Caixa}

Assaf (2000) Hedge é uma operação que reduz o risco de uma posição de caixa, estoque ou até mesmo outra operação diminuindo ou eliminando a possibilidade de perder dinheiro devido a uma alteração de taxas, índices ou preços. É uma Operação de proteção (hedge, em inglês) ou de cobertura de riscos de perda decorrentes de flutuações bruscas do preço de bens 
ou valores comprados ou vendidos.

\section{3 - METODOLOGIA}

A metodologia utilizada para análise de dados foi baseada em coleta de dados/informações a partir de relatórios referentes aos controles da tesouraria relativos a reunião anual da empresa junto a Controladoria, e foram realizadas pesquisas bibliográficas para fundamentação teórica.

\section{4 - ANÁLISE DE DADOS}

Em 1940, a empresa que originaria a Construtora ERO S.A. começava a movimentar suas primeiras betoneiras repletas de concreto.

A Construtora ERO participou ativamente de demarcações de terras, levantamentos topográficos e construções de estradas na região Sul do País, na década de 50,sendo uma das pioneiras no uso do concreto armado no Brasil.

Em 1970, houve a primeira oportunidade em terras internacionais, sendo Venezuela e Equador. Posteriormente a America Latina seria questão de tempo.

$\mathrm{Na}$ virada da década de 1980 para 1990, investimentos em negócios do setor petroquímico tornavam-se estratégicos, e a Construtora ERO S.A. estabeleceu o desafio de dar continuidade à expansão internacional. A Organização ampliou sua atuação, chegando a países como Estados Unidos, México e Malásia.

O início do novo século seria marcado pela aquisição do controle acionário da Copine, a central de matérias-primas do Polo de Camacari, na Bahia, num consórcio com o Grupo Marianu. Uma grande e competitiva empresa brasileira no setor petroquímico começava a ser desenhada. Após integrações societárias e operacionais, surgiu a Brasnet, em 2002.

Desde 2010 estamos arduamente trabalhando para os próximos eventos mundiais que ocorreram no Brasil, Copa do Mundo 2014 e Olimpíadas 2016.

O crescimento do Negócio Engenharia \& Construção da empresa ERO, demandava uma ferramenta que melhorasse e facilitasse o processo de Operações Financeiras. Anteriormente as informações eram transmitidas através de e-mails, planilhas e telefonemas, aumentando o risco e causando demora na consolidação dos dados fornecidos. Os sistemas antecessores (Oracle e MWD) não dispõem de ferramentas que consolidem de forma simples e objetiva as informações diários e mensais, prejudicando a qualidade dos processos de acompanhamento previsto versus realizado, as confirmações diárias de saques e ingressos, expectativas econômicas versus financeiras e o fechamento do caixa.

A fim de suprir essa deficiência, a empresa buscou a integração de informações relevantes para o planejamento e tomada de decisão da Tesouraria Corporativa e Controladoria. O Sistema de Gerenciamento de Operações Financeiras (T-800), simplifica o processo, automatiza sua aprovação, consolidação e contabilização, agiliza o processo de fechamento diário do caixa, define a forma de comunicação das confirmações diárias de saques e ingressos, reduz o saldo em conta corrente e disponibiliza relatórios de acompanhamento a Contabilidade Gerencial e a Controladoria.

Alguns processos da Tesouraria Corporativa e controladoria, não atendendo plenamente as expectativas das áreas, devido ao crescimento da empresa nos últimos anos e a utilização simultânea de dois sistemas financeiros não integrados (Oracle e MWD). O gerenciamento das Operações Financeiras passou a ser feito também por meio de emails e telefonemas e criou-se a necessidade da utilização do Excel como ferramenta suporte na execução de tarefas diárias, como a consolidação, confirmações e o acompanhamento do realizado. 
Essa dificuldade ou falta de comunicação entre os contratos (Obras) e a Tesouraria Corporativa (Matriz-Controladoria) gerava ineficiência na gestão do caixa. As informações recebidas diariamente eram utilizadas na decisão sobre o destino dos recursos, aplicação ou disponibilização nas contas bancárias.

A Tesouraria adotou uma postura conservadora na gestão do caixa, pois as falhas no processo acima se tornaram frequentes. Devido à incerteza da necessidade de recursos que a Matriz teria que disponibilizar para as obras, era utilizada uma margem de segurança suficiente para cobrir também as confirmações não realizadas. Por outro lado, adotando essa postura conservadora para evitar o saldo negativo nas contas bancárias, eram recorrentes sobras de elevadas quantias sem remuneração.

Outro impacto gerado pela falta de uma única ferramenta para comunicação era o aumento do tempo despendido no fechamento diário do caixa.

Após o mapeamento do cenário, verificou-se a necessidade de um Sistema de Gerenciamento de Operações Financeiras para a consolidação dos dados gerados nos diferentes sistemas utilizados e a correção dos problemas relacionados a seguir:

Comunicação: as solicitações e confirmações de remessas e ingressos à Tesouraria Corporativa eram realizadas semanalmente pelas obras de diferentes formas ou até mesmo não eram realizadas por algumas.

Praticidade: a nova ferramenta buscou simplificar e assegurar algumas atividades dos financeiros das Obras, sem deixar de atender as necessidades dos Controllers e da Tesouraria.

A falha de comunicação entre obras e Tesouraria Corporativa era resultante da complexidade no preenchimento detalhado das informações nos sistemas anteriormente utilizados.

Após solucionar a dificuldade encontrada pelas obras e em comunicar as necessidades de caixa, a Tesouraria Corporativa passou a realizar a gestão do caixa com maior qualidade e segurança empresarial. No processo de fechamento do caixa foram atingidos três objetivos: da atividade.

-melhoraria da comunicação, aumento da qualidade dos dados e redução do tempo

Devido ao comprometimento das obras, a Tesouraria passou a deixar disponível em conta apenas o montante solicitado pela somatória dos contratos, reduzindo a cada mês o saldo, sem remuneração, que anteriormente ficava parado nas contas bancárias.

\section{5 - CONSIDERAÇÕES FINAIS}

A redução do saldo em conta corrente é o principal ganho financeiro gerado pelo sistema é a redução da média mensal do saldo diário em conta corrente. Apenas nos primeiros meses de utilização, a Tesouraria e Controladoria, conseguiram aplicar aproximadamente $60 \%$ dos recursos que anteriormente permaneciam parados na conta corrente (das obras) sem remuneração, melhorando a rentabilidade das disponibilidades do Negócio.

A redução do saldo em conta, apresentada no Gráfico 3, é uma comparação do mesmo período de 2010 com 2011. Se compararmos uma aplicação dessa diferença a 100\% do CDI e, considerando o CDI $12 \%$ ao ano, à uma taxa do dólar de R\$1,70, chega-se a estimativa de ganho de $\mathrm{R} \$ 530.419,06$ (ganho financeiro).

Antes do novo sistema, o meio de comunicação para confirmação de saques e ingressos, era realizado em algumas horas através da consolidação das informações 
recebidas por telefonemas, e-mails, planilhas, análise histórica e relatórios das obras enviados por consorciadas, escritórios e matrizes. Com o novo sistema, o relatório de consolidação das informações passou a ser gerado em alguns segundos (ganho de tempo e produtividade).

A redução no tempo do processo de fechamento do caixa, a facilidade proporcionada com o sistema reduziu o tempo necessário para o fechamento do caixa e aumentou o prazo das solicitações de recursos à Tesouraria Corporativa, sem qualquer impacto no processo de fechamento do caixa.

Atualmente os relatórios de acompanhamento para Controladoria juntamente com as informações atualizadas diariamente estão disponíveis no sistema e atendem as necessidades da Tesouraria Corporativa e Controladoria. A eficiência na gestão do caixa possibilitou maior rentabilidade dos recursos financeiros, que antes ficavam na conta corrente sem remuneração (perda de dinheiro). Os novos procedimentos trouxeram diversos benefícios ao negócio, inclusive a melhoria e a ampliação do apoio aos Controllers, contratos de engenharia \& construção no Brasil pela Tesouraria Corporativa.

A partir de Junho/2011 passou-se a utilizar a ferramenta e seguramente os números tendem a melhorar a cada mês. O resultado parcial de setembro/2011 apresenta um saldo ainda elevado, entretanto, conseguiram reduzir quase $60 \%$, se comparado com o mesmo período de 2010.

\section{REFERÊNCIAS}

ASSAF. Neto. Alexandre. Mercado Financeiro. 4 ed. São Paulo: Editora Atlas, 2001.

BATISTA, Emerson de Oliveira. Sistema de Informação: o uso consciente da tecnologia para o gerenciamento. São Paulo: Saraiva 2004.

CARVALHO, Marly Monteiro. Gestão de Qualidade: Teoria e Casos. 5.ed.Rio de Janeiro:Editora Elsevier.

CATTELI, Armando. Controladoria: uma abordagem da gestão econômica - GECON.São Paulo: Atlas, 1999.

CATELli, Armando (Coord.). Controladoria. São Paulo: Atlas, 2001. ETZIONI, Amitai. Organizações modernas. São Paulo: Pioneira, 1980.

CHIAVENATO, Idalberto. Administração: Teoria, Processo e Prática. 3. ed. São Paulo: Pearson Education do Brasil, 2000.

FIGUEIREDO, Sandra; CAGGIANO, Paulo Cesar. Controladoria - Teoria e Prática. São Paulo: Atlas, 1997.

GARCIA, Elias; GARCIA, Osmarina Pedro Garcia. A importância do sistema de informação gerencial para a gestão empresarial. Revista Ciências Sociais em Perspectiva, do Centro de Ciências Sociais Aplicadas de Cascavel, Cascavel, v.2, n.1, p. 21-32, 1 sem.2003.

GARRISON, Ray H.; NOREEN, Eric W. Contabilidade gerencial. Rio de Janeiro: LTC, 2001.

GIL, Antonio de Loureiro. Sistemas de informações: contábil, financeiros. 3 ed. São Paulo: 
Editora Atlas, 1999.

GOMES, C. F. S, ALMEIDA, A. T., Tomada de Decisão Gerencial: Enfoque Multicritério, Ed. Atlas, São Paulo, 2006

HAZAN, Samuel. POMPEO, José Nicolau. Matemática Financeira. 6.ed.São Paulo:Editora Saraiva,2007.

IUDÍCIBUS, Sérgio de; MARION, José Carlos. Contabilidade Comercial. 4. ed. São Paulo: Atlas, 2000.

LAUDON, Kenneth C. e LAUDON, Jane Price. Sistemas de Informação. 4. ed. LTC: Rio de Janeiro, 1999.

. Gerenciamento de sistemas de informação, 3. ed. LTC: Rio de Janeiro, 2001.

MOSSIMANN; ALVES; FISCH. Controladoria: seu papel na administração das empresas. Florianópolis: Ed. da UFSC, Fundação ESAG, 1993.

NAKAGAWA, Masayuki. Introdução à Controladoria - Conceitos, Sistemas, Implementação. São Paulo: Atlas, 1993.

OLIVEIRA, Djalma de Pinho Rebouças. Sistemas de informações gerenciais. São Paulo: Atlas, 1992.

OLIVEIRA, Martins de; NAGATSUKA, Diviane A. S.. Introdução à Contabilidade. São Paulo: Futura, 2000.

OLIVEIRA, Djalma de Pinho Rebouças. Sistemas, Organizações e Métodos: uma Abordagem Gerencial. 13. Ed São Paulo, 2002, Paulo, 2002

PADOVEZE, Clovis Luis. Contabilidade gerencial: um enfoque em sistema de informação contábil. São Paulo: Ed Atlas, 1993.

PEREIRA, Maria José Lara de Bretãs; FONSECA, João Gabriel Marques. Faces da Decisão: as mudanças de paradigmas e o poder da decisão. São Paulo: Makron Books, 1997.

REZENDE, Denis Alcides; ABREU, Aline França de. Tecnologia de informação aplicada a sistemas de informação empresariais. São Paulo: Atlas, 2000.

RIBEIRO, Osni Moura. Contabilidade Básica fácil. São Paulo. 21. Ed. Editoria Saraiva. 1997.

STEPHEN P. Robbies.; COULTER, Mary. Administração. 5. ed. Prentice. Hall Interamericana, 1996.

STEPHEN. A.Ross; RANDOLPH. W. Westerfield e BRANDFORD,D. Jordan.Princípios de administração Financeira. 2. ed.São Paulo:Editora Atlas,2000.

STONER, James A. F.; FREEMAN, R. Edwards. Administração. 5. ed. Rio de Janeiro:LTC, 1999.

STAIR, Ralph M. Princípios de sistemas de informação: uma abordagem gerencial. Rio de Janeiro: LTC, 1998. 
WELSCH, Glenn Albert. Orçamento empresarial. São Paulo, Atlas: 1992. 